\title{
SISTEM PENERIMAAN PEGAWAI SALES KPR PADA BANK MENGGUNAKAN METODE MULTI-OBJECTIVE OPTIMIZATION ON THE BASIS OF RATIO ANALYSIS
}

\author{
Andreyan Rizky Baskara, Yuslena Sari, Muhammad Adetya Anshari \\ Program Studi Teknologi Informasi, Universitas Lambung Mangkurat \\ Jl. Brigjen H. Hasan Basri Banjarmasin 70123 \\ andreyan.baskara@ulm.ac.id,yuzlena@ulm.ac.id,m.adetyaashari@gmail.com
}

\begin{abstract}
The recruitment of new employees, especially for housing loan sales employees (KPR) is often carried out by banks because the performance evaluation of KPR sales employees is carried out regularly. The large number of prospective employees and the variety of criteria determined for selecting new employees lead to a lengthy decision-making process. Decision Support System (DSS) is basically a comprehensive computer system that can help make decisions and solve problems. The Multi Objective Optimization method on The Basis of Ratio Analysis (MOORA) as a decision-making method is used to build a decision support system. The decision support system is implemented as a web-based application using ATOM software which is integrated with the MYSQL database. The Black Box testing method is used to test the system. The results showed that the MOORA method is very suitable to be applied in the decision making of KPR sales employee recruitment
\end{abstract}

Keywords: Decision Support System, KPR Sales Employee, MOORA

Abstrak

Perekrutan pegawai baru khususnya untuk pegawai Sales Kredit Pemilikan Rumah (KPR) sering dilakukan oleh bank karena evaluasi kinerja pegawai sales KPR dilakukan secara berkala. Banyaknya calon pegawai dan beragamnya kriteria-kriteria yang ditentukan untuk menseleksi pegawai baru menyebabkan lamanya proses pengambilan keputusan. Sistem Pendukung Keputusan (SPK) pada dasarnya adalah sistem komputer komprehensif yang dapat membantu membuat keputusan dan menyelesaikan masalah. Metode Multi Objective Optimization on The Basis of Ratio Analysis (MOORA) sebagai salah satu metode pengambilan keputusan digunakan untuk membangun sistem pendukung keputusan. Sistem pendukung keputusan diimplementasikan sebagai aplikasi berbasis web menggunakan perangkat lunak ATOM yang terintegrasi dengan database MySQL. Metode pengujian Black Box digunakan untuk menguji sistem. Hasil penelitian menunjukkan bahwa metode MOORA sangat cocok diterapkan dalam pengambilan keputusan perekrutan pegawai sales KPR

Kata kunci: MOORA, Pegawai Sales KPR, Sistem Penunjang Keputusan 


\section{PENDAHULUAN}

Undang-undang Nomor 10 Tahun 1998 menyebutkan Bank sebagai badan usaha yang mengumpulkan dana dari masyarakat dalam bentuk simpanan dan menyalurkannya kepada masyarakat dalam bentuk kredit dan atau bentuk-bentuk lainnya dalam rangka meningkatkan taraf hidup masyarakat [1]. Bank secara umum dapat diartikan suatu lembaga yang melaksanakan kegiatan usaha secara konvensional dan atau berdasarkan prinsip Syariah, yang dalam kegiatannya memberikan jasa dalam lalu lintas pembayaran. Bank memiliki berbagai macam kegiatan usaha, salah satunya yaitu Kredit Pemilikan Rumah (KPR) [2][3].

KPR merupakan fasilitas kredit yang diberikan untuk membeli rumah atau untuk kebutuhan konsumtif lainnya dengan jaminan/agunan berupa rumah [4]. KPR memiliki berbagai macam produk sehingga untuk memasarkannya diperlukan bagian marketing/sales. Pada suatu Bank, Unit Consumer Loan merupakan unit yang bergerak pada segmen KPR, dimana unit tersebut yang melakukan rekrutmen terhadap marketing/sales KPR [5] [6].

Pada unit Consumer Loan sales KPR diberikan pembekalan sebelum mulai bekerja. Namun setelah mulai bekerja, sering kali mendapati sales tersebut hanya bertahan dalam jangka waktu yang pendek saja [7]. Dikarenakan sales tersebut diterminasi oleh pihak perusahaan. Terminasi tersebut dilakukan pertiga bulan oleh perusahaan, apabila sales ini tidak memiliki kemampuan dan tidak menunjukan kinerja yang baik serta tidak mencapai target penjualan yang sudah ditentukan maka perusahaan akan melakukan terminasi terhadap sales tersebut. Oleh karena itu perusahaan akan mencari calon pegawai baru.

Dengan semakin banyaknya pelamar baru dengan kualifikasi dan kemampuan yang berbeda-beda maka diperlukan penyeleksian terhadap calon marketing/sales baru yang melamar pada unit Consumer Loan. Dalam prosesnya, bagian rekrutmen terkadang kesulitan melakukan seleksi dikarenakan jumlah calon marketing/sales yang banyak dan juga keterbatasan waktu manajer serta tingkat mobilitasnya yang tinggi sehingga rawan akan terjadinya kesalahan dalam mengambil keputusan.

Karena dampak kesalahan rekrutmen bagi Unit Consumer Loan cukup besar, harus ada proses rekrutmen yang lebih efektif baik dari proses administrasi maupun proses seleksi. Solusi yang akan dibuat adalah dengan menerapkan sistem pendukung keputusan (SPK) yang akan membantu manajer dalam mengambil keputusan untuk penilaian calon marketing/sales baru.

SPK merupakan sistem komputer yang memiliki sifat komprehensif dengan alat-alat yang saling terhubung untuk membantu membuat keputusan dan pemecahan masalah [8]. Aplikasi SPK menggunakan CBIS (Computer Based Information System) yang memiliki karakteristik fleksibel, interaktif, dan dapat mudah untuk diadaptasi serta mudah dikembangkan untuk memberikan solusi atas masalah yang kompleks atau tidak terstruktur sehingga dapat meningkatkan proses pengambilan keputusan yang dilakukan oleh manajemen akan tetapi tidak mengganti posisi manusia sebagai pengambil keputusan [9].

Penelitian tentang sistem penunjang keputusan sudah banyak dilakukan, salah satunya oleh Sri Anjarwati, dkk dimana pada penelitiannya, dibuat sistem 
hirarki dengan kriteria-kriteria penyeleksian antara lain: Nilai Pendidikan (IPK/rata-rata), Nilai Psikotes, Nilai Tes Tulis dan Nilai Wawancara [10]. Penelitian lainnya juga dilakukan oleh Yessica Siagian dimana pada penerapannya, penggunaan metode TOPSIS dianggap mampu membantu perusahaan dalam memilih karyawan baru berdasarkan konsepnya dimana alternatif terbaik dipilih dengan kriteria yang telah ditentukan [11]. Penelitian serupa juga dilakukan oleh Ardhi Bagus Primahudi, dkk dimana pada penelitiannya menerapkan metode Simple Adaptive Weighting (SAW) dan sistem dikembangan dengan Bahasa pemprograman php dan xampp, dengan menghitung bobot kriteria dan ranking untuk sistem penyeleksiannya [12].

Selanjutnya, Hasibuan dkk. melakukan penelitian komparasi antara metode MOORA dan TOPSIS dalam studi kasus penentuan penerimaan siswa baru. Hasil dari penelitian yang dilakukan menunjukkan bahwa metode MOORA memiliki sensitivitas yang lebih besar dari pada metode TOPSIS [13]. Sehingga pada penelitian ini dipilihlah metode MOORA sebagai metode pengambilan keputusan yang akan diterapkan di dalam sistem penunjang keputusan.

Penelitian ini memiliki tujuan untuk menerapkan metode MOORA pada sistem pendukung keputusan seleksi calon pegawai sales KPR pada sebuah bank di Banjarmasin berdasarkan kriteria yang telah ditetapkan perusahaan. Sistem yang dibangun pada penelitian ini diharapkan dapat membantu bagian rekrutmen dan HRD pada bank untuk mengambil keputusan dalam menerima pegawai sales KPR baru.

\section{METODOLOGI PENELITIAN}

Bahan penelitian yang akan digunakan pada penelitian ini adalah data kriteria pegawai sales beserta nilai bobot pada masing-masing kriteria tersebut yang didapat dari bagian rekrutmen dan HRD pada Bank ABC di daerah Banjarmasin. Adapun prosedur penelitian yang dilakukan dapat dilihat pada Gambar 1.

Tahap pertama yang dilakukan adalah Identifikasi Masalah yaitu, mempelajari konsep sistem pendukung keputusan, kriteria dan bobot yang digunakan, serta tahapan-tahapan dalam perhitungan metode MOORA. Selanjutnya dilakukan tahapan Pengumpulan Data. Pada tahapan ini yang akan dilakukan adalah mengumpulkan data sesuai dengan topik yang akan diambil dengan cara studi pustaka, wawancara dan observasi. Data yang dikumpulkan berupa kriteria beserta nilai bobotnya yang merupakan data primer. 


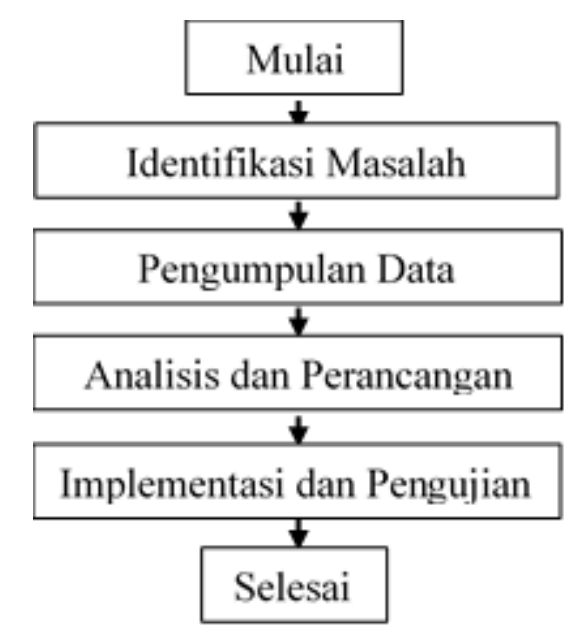

Gambar 1. Alur prosedur penelitian

Tahap ketiga adalah Analisis dan Perancangan. Keseluruhan data yang telah dikumpulkan akan dianalisis dan data akan diolah menggunakan metode MOORA. Kemudian dilanjutkan dengan perancangan sistem sesuai dengan kebutuhan awal berdasarkan analisis data yang telah dilakukan.

Tahap keempat adalah Implementasi dan Pengujian. Tahap ini akan mengimplementasikan dan melakukan pengujian untuk mengetahui hasil kerja sistem dan tingkat kesesuaian yang diperoleh dari metode yang digunakan dalam penyeleksian pegawai baru (Sales).

\subsection{Identifikasi Masalah}

Dengan terus meningkatnya jumlah para pelamar pekerjaan dengan berbagai macam kemampuan yang berbeda-beda maka diperlukan alat bantu berupa sistem pendukung keputusan yang akan memberikan informasi langsung kepada Manajer berupa daftar calon pegawai baru yang sesuai dengan kriteria yang sudah ditentukan oleh Perusahaan.

Pada tahapan ini dilakukan wawancara langsung dengan HRD yang diwakili oleh bagian admin pada Bank ABC di daerah Banjarmasin. Topik yang dibahas yaitu tentang proses seleksi penerimaan pegawai baru. Penerimaan pegawai sales KPR pada Bank ABC dilakukan dalam rentang waktu sekitar setiap 3 bulan dikarenakan seringnya terjadi target yang tidak tercapai oleh pegawai sales sehingga menurunkan kinerja pada bagian marketing dan akhirnya menyebabkan pegawai tersebut harus diterminasi oleh perusahaan. Dalam prosesnya, bagian rekrutmen terkadang kesulitan melakukan seleksi dikarenakan jumlah calon marketing/sales yang banyak dan juga keterbatasan waktu manajer serta tingkat mobilitasnya yang tinggi sehingga rawan akan terjadinya kesalahan dalam mengambil keputusan.

\subsection{Pengumpulan Data}

Pengumpulan data pada penelitian ini dilakukan dengan menggunakan metode pengumpulan data studi pustaka dan wawancara. Studi pustaka 
merupakan teknik pengumpulan data dengan melakukan penelaahan terhadap berbagai macam referensi seperti buku, literatur dan catatan serta berbagai jenis laporan, makalah atau jurnal yang dijadikan sumber referensi dan teori-teori dalam penelitian. Studi pustaka yang akan digunakan dalam penelitian ini tentunya berkaitan dengan topik pembahasan yaitu sistem pendukung keputusan dan metode MOORA. Semua referensi yang digunakan baik dari buku, jurnal, e-book dan internet tercantum dalam daftar pustaka.

Pengumpulan data dengan metode wawancara dilakukan kepada bagian admin di Bank $\mathrm{ABC}$ di daerah Banjarmasin dengan topik yang dibahas yaitu tentang proses seleksi penerimaan pegawai baru. Sedangkan kriteria dan bobot yang akan digunakan diperoleh dari wawancara dengan Relationship Manager.

Tahapan selanjutnya yaitu analisis data adalah menganalisa data yang diperlukan pada studi kasus penelitian ini. Adapun data yang diperlukan adalah berupa kriteria yang sudah ditentukan seperti Jenjang Pendidikan (S-1), Nilai Psikotes, Nilai Tes Tulis, Nilai Wawancara, Pengalaman Kerja, Umur, Status Perkawinan. Masing-masing kriteria memiliki nilai bobot atau standar nilai yang sudah ditentukan oleh perusahaan.

\subsection{Analisis dan Perancangan}

Penelitian ini akan menerapkan sebuah sistem pendukung keputusan penerimaan calon pegawai baru dengan menggunakan metode MOORA sebagai metode perhitungannya. Sistem yang dibuat akan membantu memberikan rekomendasi calon pegawai baru berdasarkan kriteria dan nilai bobotnya. Perancangan sistem diperlukan untuk menjelaskan bagaimana proses atau jalannya perangkat lunak. Pada penelitian ini proses jalannya sistem dapat digambarkan dengan sederhana melalui diagram alur yang ditunjukkan pada Gambar 2.

Sistem dibagi menjadi dua modul, yaitu modul admin dan modul manajer. Modul admin digunakan oleh staff admin untuk mengisikan data terkait calon pegawai sesuai kriteria yang ditentukan. Setelah itu admin dapat memilih untuk melakukan perangkingan data calon pegawai dengan menggunakan metode MOORA. Kemudian sistem menampilkan hasil rekomendasi perangkingan calon pegawai dimana diurutan teratas adalah calon pegawai yang paling sesuai dengan kriteria yang sudah ditentukan.

Pada modul manajer, para atasan yang berwenang terhadap perekrutan calon pegawai sales baru dapat melihat hasil rekomendasi perangkingan sehingga dapat membantu mengambil keputusan calon pegawai mana yang akan direkrut. 


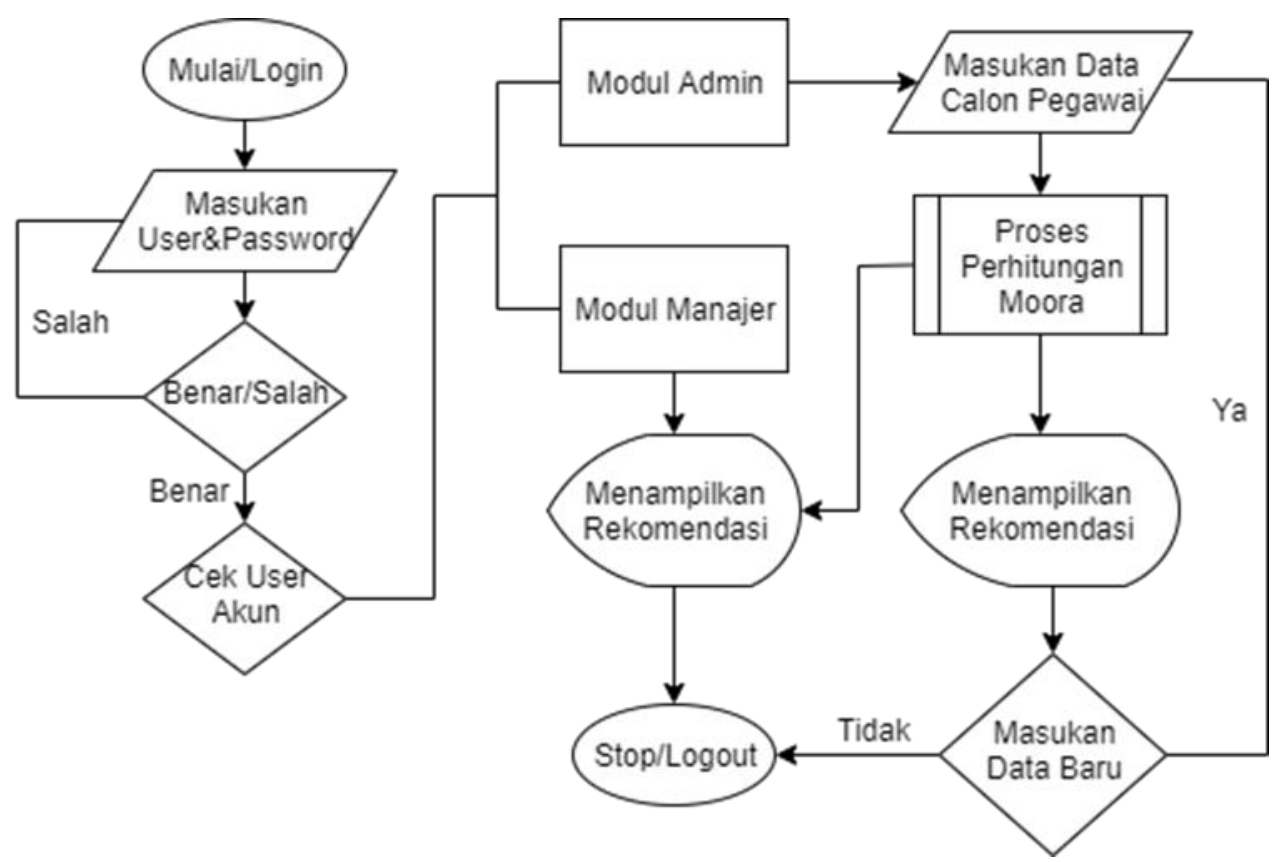

Gambar 2. Diagram alur jalannya sistem

\subsection{Implementasi dan Pengujian}

Sistem yang sudah dirancang selanjutnya diimplementasikan menggunakan perangkat lunak ATOM, dengan bahasa pemprograman PHP, Laravel Framework, dan menggunakan database MySQL. Hal yang pertama kali dilakukan dalam membangun sistem penunjang keputusan adalah membuat struktur basis pengetahuan. Basis pengetahuan merupakan kumpulan-kumpulan fakta. Beberapa struktur basis pengetahuan dalam sistem penunjang keputusan pada penelitian ini adalah sebagai berikut:

1. Basis pengetahuan kriteria

2. Basis pengetahuan bobot

3. Basis pengetahuan alternative

Pada basis pengetahuan berisikan tentang jenis kriteria, bobot pada masing-masing kriteria dan jumlah alternative yang akan diproses. Basis pengetahuan akan dijabarkan dalam bentuk Tabel 1. Basis pengetahuan alternative merupakan daftar nama calon pegawai baru.

Pengujian dilakukan menjadi 2 tahapan, pertama pengujian sistem menggunakan pengujian Black Box dan kedua pengujian performa metode dengan menggunakan matriks akurasi. Pengujian performa metode dilakukan dengan membandingkan data hasil rekrutmen yang sudah dilakukan Bank ABC sebelumnya dibandingkan dengan hasil perangkingan dari sistem dengan metode MOORA. 
Tabel 1. Basis Pengetahuan Kriteria dan Bobot

\begin{tabular}{clcc}
\hline Kriteria & \multicolumn{1}{c}{ Keterangan } & Bobot \\
\hline C1 & IPK (S1) & 0.25 & Benefit \\
C2 & Usia & 0.1 & Cost \\
C3 & Pengalaman Kerja & 0.2 & Benefit \\
C4 & Nilai Wawancara & 0.15 & Benefit \\
C5 & Nilai Psikotest & 0.15 & Benefit \\
C6 & Nilai Tes Tertulis & 0.15 & Benefit \\
\hline
\end{tabular}

Keterangan :

C1 : id untuk Kriteria 1

C2 : id untuk Kriteria 2

Cn : id untuk Kriteria "n"

Benefit : Jenis kriteria jika nilai semakin besar maka semakin baik, jika semakin kecil maka bernilai tidak baik

Cost : Jenis kriteria jika nilai semakin kecil maka semakin baik, jika semakin besar maka bernilai tidak baik.

\subsubsection{Impelementasi Metode MOORA}

Adapun tahapan pemrosesan metode MO0RA, adalah sebagai berikut:

Tahap 1: Membuat matrik keputusan

Matriks keputusan direpresentasikan sebagai matriks Xij. Dimana 'I' adalah ' $\mathrm{m}$ ' yang merupakan jumlah alternative sedangkan 'j' mewakili ' $n$ ' dalam jumlah kriteria, persamaan adalah representasi matriks dari keputusan [14].

$$
x=\left|\begin{array}{cccc}
x_{11} & x_{12} & * & x_{1 \mathrm{n}} \\
x_{21} & x_{22} & * & x_{2 \mathrm{n}} \\
* & * & * & * \\
x_{\mathrm{m} 1} & x_{\mathrm{m} 2} & * & x_{\mathrm{mn}}
\end{array}\right|
$$

Tahap 2: Normalisasi matriks keputusan

Untuk tahap normalisasi, opsi terbaik adalah akar kuadrat dari jumlah kuadrat dari setiap alternative per atribut. Rasio ini dapat dinyatakan sebagai berikut:

$$
x_{i j}=x_{i j} / \sqrt{\left[\sum_{i=1}^{m} x_{i j}^{2}\right](j=1,2, \ldots, n)} .
$$

\section{Tahap 3: Optimasi nilai maksimum dan minimum}

Untuk optimalisasi multi-objektif, kinerja yang dinormalisasi ini ditambahkan jika maksimalisasi (untuk atribut yang menguntungkan) dan dikurangi jika minimisasi (untuk atribut yang tidak bermanfaat). Jika tidak ditentukan bobot untuk masingmasing kriteria, maka cara optimasinya menjadi:

$$
y_{i}=\sum_{j=1}^{g} x_{i j}^{*}-\sum_{j=g+1}^{n} x_{i j}^{*}
$$


Dimana 'g' adalah jumlah atribut yang akan dimaksimalkan, (n-g) adalah jumlah atribut yang harus diminimalkan, dan 'yi' adalah nilai normalisasi terhadap semua atribut. Dalam beberapa kasus, sering terjadi bahwa beberapa attribute lebih penting daripada atribut lainnya. Untuk memberikan atribut yang lebih penting, dapat dikalikan dengan bobot yang sesuai.

Ketika bobot atribut diberikan untuk masing-masing kriteria, persamaan yang digunakan adalah sebagai berikut:

$$
y_{i}=\sum_{j=1}^{g} w_{j} x_{i j}^{*}-\sum_{j=g+1}^{n} w_{j} x_{i j}^{*} \quad(j=1,2, \ldots, n)
$$

Dimana 'wj' adalah bobot atribut 'j'

\section{Tahap 4: Menentukan rangking dari hasil perhitungan MOORA}

Nilai yang terbaik dari alternative yang dihitung merupakan nilai yang tertinggi. Nilai "yi" bisa positif atau negatif tergantung pada jumlah maksimalnya dan jumlah minimalnya dalam matriks keputusan.

\section{HASIL DAN PEMBAHASAN}

Sistem pendukung keputusan untuk seleksi penerimaan pegawai sales KPR menggunakan metode MOORA diimplementasikan menggunakan Bahasa pemrograman PHP dengan framework Laravel. Basis data yang digunakan adalah MySQL. Terdapat dua modul pada sistem yang telah dibuat, yaitu modul admin dan modul manajer.

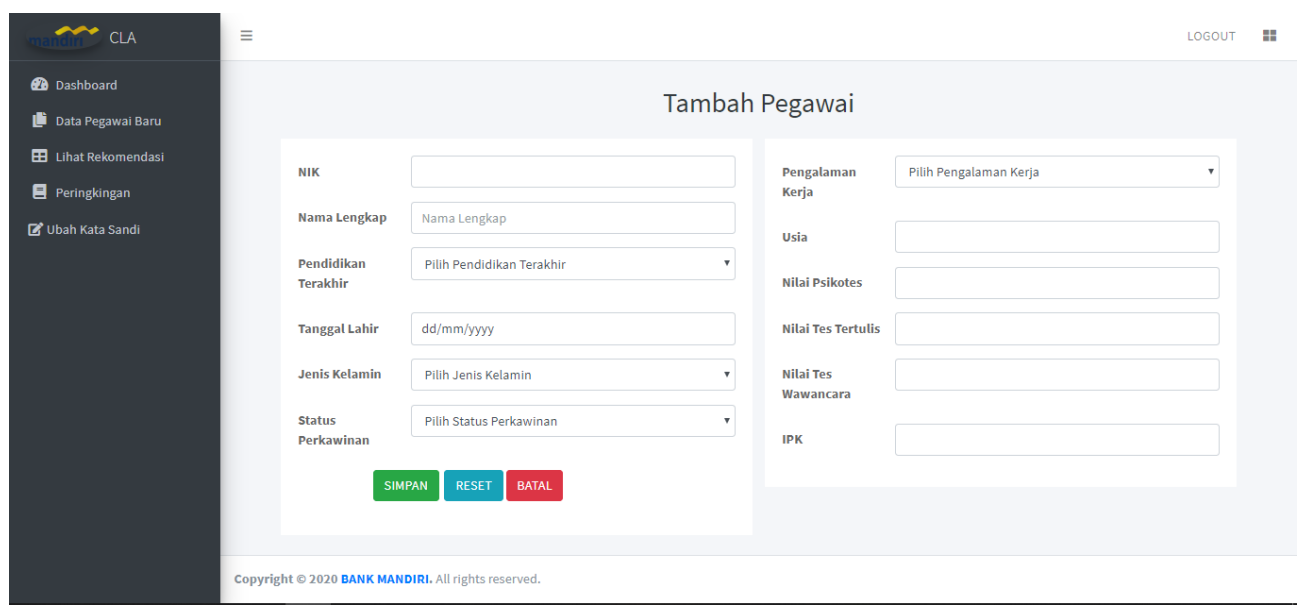

Gambar 3. Halaman Tambah Data Calon Pegawai 


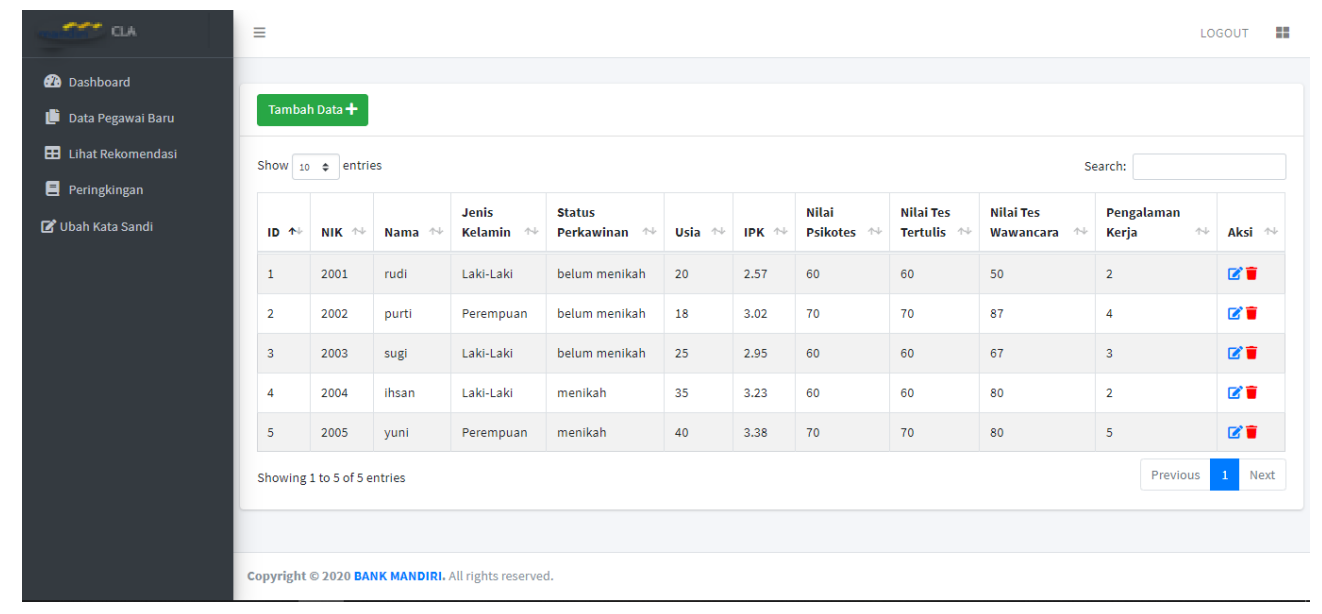

Gambar 4. Halaman Daftar Data Calon Pegawai

Modul admin digunakan oleh staff admin untuk mengisi data calon pegawai baru yang mengikuti seleksi penerimaan pegawai baru. Halaman untuk menambahkan data calon pegawai dan daftar calon pegawai dapat dilihat pada Gambar 3 dan Gambar 4. Modul manajer digunakan oleh atasan yang berwenang untuk melakukan perekrutan pegawai baru agar dapat melihat hasil rekomendasi calon pegawai baru oleh sistem. Halaman hasil rekomendasi perangkingan dapat dilihat pada Gambar 5.

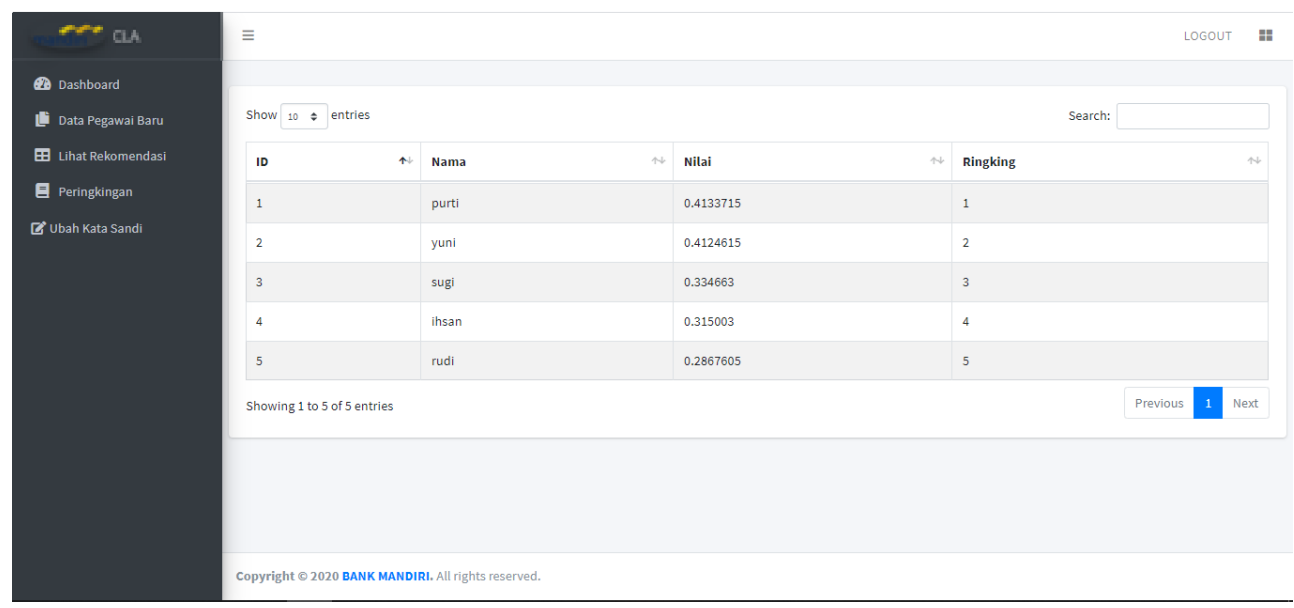

Gambar 5. Halaman Rekomendasi Perangkingan oleh Sistem

Pengujian sistem dilakukan dengan menggunakan metode Black Box Testing. Sistem memiliki 7 fungsionalitas yang diujikan masukan dan dicek keluarannya apakah sudah sesuai dengan yang diharapkan. Hasil pengujian menunjukkan bahwa sistem yang dibangun sudah menghasilkan keluaran yang diharapkan. Adapun data uji yang diperoleh adalah dari bank ABC di daerah Banjarmasin untuk seleksi pegawai sales KPR dan dapat dilihat pada Tabel 2. 
Tabel 2. Data Uji yang Digunakan

\begin{tabular}{ccccccc}
\hline Alternatif & C1 & C2 & C3 & C4 & C5 & C6 \\
\hline A1 & 3.31 & 31 & 4 & 60 & 50 & 60 \\
A2 & 3.09 & 26 & 3 & 70 & 87 & 70 \\
A3 & 3.43 & 24 & 2 & 60 & 67 & 60 \\
A4 & 3.29 & 25 & 2 & 60 & 80 & 60 \\
A5 & 3.56 & 32 & 5 & 70 & 80 & 70 \\
A6 & 2.98 & 24 & 2 & 70 & 65 & 70 \\
A7 & 3.10 & 27 & 2 & 70 & 75 & 70 \\
A8 & 3.38 & 29 & 2 & 60 & 80 & 60 \\
A9 & 3.41 & 24 & 1 & 60 & 80 & 60 \\
A10 & 3.24 & 26 & 2 & 70 & 80 & 70 \\
A11 & 3.06 & 25 & 2 & 70 & 65 & 70 \\
A12 & 3.19 & 29 & 4 & 70 & 75 & 70 \\
A13 & 3.37 & 27 & 2 & 60 & 80 & 60 \\
A14 & 3.49 & 27 & 2 & 70 & 80 & 70 \\
A15 & 3.22 & 26 & 1 & 70 & 65 & 70 \\
\hline
\end{tabular}

Selanjutnya pada metode MOORA, dilakukan proses normalisasi data menggunakan persamaan 2 untuk setiap alternatif dan setiap kriteria, sehingga didapatkan hasil seperti ditunjukkan pada Tabel 3.

Tabel 3. Hasil normalisasi

\begin{tabular}{ccccccc}
\hline Alternatif & C1 & C2 & C3 & C4 & C5 & C6 \\
\hline A1 & 0.26 & 0.2975 & 0.3922 & 0.2341 & 0.1733 & 0.2341 \\
A2 & 0.24 & 0.2495 & 0.2942 & 0.2731 & 0.3015 & 0.2731 \\
A3 & 0.27 & 0.2303 & 0.1961 & 0.2341 & 0.2322 & 0.2341 \\
A4 & 0.26 & 0.2399 & 0.1961 & 0.2341 & 0.2772 & 0.2341 \\
A5 & 0.28 & 0.3071 & 0.4903 & 0.2731 & 0.2772 & 0.2731 \\
A6 & 0.23 & 0.2303 & 0.1961 & 0.2731 & 0.2252 & 0.2731 \\
A7 & 0.24 & 0.2591 & 0.1961 & 0.2731 & 0.2599 & 0.2731 \\
A8 & 0.27 & 0.2783 & 0.1961 & 0.2341 & 0.2772 & 0.2341 \\
A9 & 0.27 & 0.2303 & 0.0981 & 0.2341 & 0.2772 & 0.2341 \\
A10 & 0.26 & 0.2495 & 0.1961 & 0.2731 & 0.2772 & 0.2731 \\
A11 & 0.24 & 0.2399 & 0.1961 & 0.2731 & 0.2252 & 0.2731 \\
A12 & 0.25 & 0.2783 & 0.3922 & 0.2731 & 0.2599 & 0.2731 \\
A13 & 0.27 & 0.2591 & 0.1961 & 0.2341 & 0.2772 & 0.2341 \\
A14 & 0.27 & 0.2591 & 0.1961 & 0.2731 & 0.2772 & 0.2731 \\
A15 & 0.25 & 0.2495 & 0.0981 & 0.2731 & 0.2252 & 0.2731 \\
\hline
\end{tabular}


Selanjutnya, Hasil normalisasi dikalikan dengan bobotnya yang telah ditentukan untuk masing-masing kriteria pada Tabel 1, sehingga didapatkan hasil seperti ditunjukkan pada Tabel 4.

Tabel 4. Hasil perkalian bobot dan normalisasi

\begin{tabular}{ccccccc}
\hline \multirow{2}{*}{ Alternatif } & C1 & C2 & C3 & C4 & C5 & C6 \\
\hline A1 & 0.07 & 0.0297 & 0.0784 & 0.0351 & 0.0260 & 0.0351 \\
A2 & 0.06 & 0.0249 & 0.0588 & 0.0410 & 0.0452 & 0.0410 \\
A3 & 0.07 & 0.0230 & 0.0392 & 0.0351 & 0.0348 & 0.0351 \\
A4 & 0.06 & 0.0240 & 0.0392 & 0.0351 & 0.0416 & 0.0351 \\
A5 & 0.07 & 0.0307 & 0.0981 & 0.0410 & 0.0416 & 0.0410 \\
A6 & 0.06 & 0.0230 & 0.0392 & 0.0410 & 0.0338 & 0.0410 \\
A7 & 0.06 & 0.0259 & 0.0392 & 0.0410 & 0.0390 & 0.0410 \\
A8 & 0.07 & 0.0278 & 0.0392 & 0.0351 & 0.0416 & 0.0351 \\
A9 & 0.07 & 0.0230 & 0.0196 & 0.0351 & 0.0416 & 0.0351 \\
A10 & 0.06 & 0.0249 & 0.0392 & 0.0410 & 0.0416 & 0.0410 \\
A11 & 0.06 & 0.0240 & 0.0392 & 0.0410 & 0.0338 & 0.0410 \\
A12 & 0.06 & 0.0278 & 0.0784 & 0.0410 & 0.0390 & 0.0410 \\
A13 & 0.07 & 0.0259 & 0.0392 & 0.0351 & 0.0416 & 0.0351 \\
A14 & 0.07 & 0.0259 & 0.0392 & 0.0410 & 0.0416 & 0.0410 \\
A15 & 0.06 & 0.0249 & 0.0196 & 0.0410 & 0.0338 & 0.0410 \\
\hline
\end{tabular}

Tahap terakhir yaitu perhitungan optimisasi dan perangkingan. Tahap ini menghitung optimisasi (Yi) dari total nilai semua kriteria bertipe benefit dikurangkan dengan total nilai semua kriteria bertipe cost seperti pada persamaan 4. Hasil dari perangkingannya ditunjukkan pada Tabel 5. Rangking paling atas menunjukkan bahwa calon pegawai tersebut paling sesuai dengan kriteria calon pegawai baru yang dicari.

Tabel 5. Hasil Optimasi MOORA dan Perangkingan

\begin{tabular}{llrrr}
\hline Alternatif & Max & \multicolumn{1}{l}{ Min } & Yi (Max-Min) & Ranking \\
\hline A5 & 0.2917 & 0.030707 & 0.260949 & 1 \\
A12 & 0.2622 & 0.027828 & 0.234333 & 2 \\
A2 & 0.2468 & 0.024949 & 0.221868 & 3 \\
A1 & 0.2398 & 0.029747 & 0.210078 & 4 \\
A14 & 0.2314 & 0.025909 & 0.205534 & 5 \\
A10 & 0.2265 & 0.024949 & 0.201571 & 6 \\
A7 & 0.2212 & 0.025909 & 0.195257 & 7 \\
A4 & 0.2158 & 0.02399 & 0.191811 & 8 \\
A13 & 0.2174 & 0.025909 & 0.191467 & 9 \\
A11 & 0.2152 & 0.02399 & 0.191191 & 10 \\
A6 & 0.2136 & 0.02303 & 0.190575 & 11
\end{tabular}




\begin{tabular}{lrrrr} 
A8 & 0.2176 & 0.027828 & 0.189745 & 12 \\
A3 & 0.2118 & 0.02303 & 0.18877 & 13 \\
A9 & 0.1986 & 0.02303 & 0.175522 & 14 \\
A15 & 0.1987 & 0.024949 & 0.17377 & 15 \\
\hline
\end{tabular}

Selanjutnya dilakukan pengujian untuk mengetahui performa metode yang telah diimplementasikan. Hal ini dilakukan dengan membandingkan antara data penerimaan pegawai sales KPR yang sudah dilakukan oleh Bank ABC sebelumnya dengan hasil perangkingan dari sistem dan kemudian dihitung tingkat akurasinya. Ada 3 calon pegawai yang diterima dari data sebelumnya, sehingga Hasil yang dibandingkan adalah hasil perangkingan tiga teratas oleh sistem. Hasil perbandingan ditunjukkan pada Tabel 6. Ketiga pegawai yang diterima oleh Bank $\mathrm{ABC}$ diberikan ranking teratas oleh metode MOORA. Hal ini menunjukkan bahwa Metode MOORA sangat efektif dan sesuai untuk kasus seleksi penerimaan pegawai sales KPR.

Tabel 6. Perbandingan Hasil Metode MOORA dan Data Sebenarnya

\begin{tabular}{ccc} 
Hasil Metode Moora & Data Sebenarnya & Keterangan \\
\hline A5 & A5 & Sesuai \\
A12 & A12 & Sesuai \\
A2 & A2 & Sesuai \\
\hline
\end{tabular}

\section{SIMPULAN}

Paper ini membahas tentang implementasi metode MOORA untuk sistem penunjang keputusan seleksi pegawai sales KPR bank. Kriteria yang digunakan untuk seleksi sudah ditentukan seperti Nilai IPK Sarjana (S-1), Nilai Psikotes, Nilai Tes Tulis, Nilai Wawancara, Pengalaman Kerja, dan Usia. Masing-masing kriteria memiliki nilai bobot atau standar nilai yang sudah ditentukan oleh perusahaan. Hasil pengujian menunjukkan metode MOORA sangat efektif dengan tingkat keakuratan $100 \%$.

\section{DAFTAR PUSTAKA}

[1] M. M. Auliani and Syaichu, "Analisis Pengaruh Faktor Internal dan Faktor Eksternal Terhadap Tingkat Pembiayaan Bermasalah pada Bank Umum Syariah Di Indonesia Periode Tahun 2010-2014", Diponegoro Journal of Management, 2016.

[2] OJK, "Perbankan," Otoritas Jasa Keuangan. 2017.

[3] I. Nendi, "Implementasi Strategi Pemasaran Kredit Kepemilikan Rumah (KPR) di Bank Muamalat Cabang Cirebon", Syntax Literate Jurnal Ilmiah Indonesia, 2016.

[4] B. Fachrizal, I. F. Astuti, and D. M. Khairina, "Sistem Pendukung Keputusan untuk Kredit Pemilikan Rumah Bank Uob Menggunakan Metode Simple 
Additive Weighthing", Informatika Mulawarman Jurnal Ilmiah Ilmu Komputer, 2013.

[5] M. Discussion, “Analisa dan pembahasan manajemen”, pp. 33-54, 2013.

[6] K. Y. Putri, “Consumer Loan”, p. 1, 2019.

[7] T. Hasih, "Sistem Pembayaran Kredit Pemilikan Rumah (KPR) Melalui Angsuran Kolektif Pada PT. Bank Tabungan Negara (Persero) Cabang Solo", 2010.

[8] Syafaruddin and Anzizhan, "Sistem Pengambilan Keputusan Pendidikan", p. 139, 2004, doi: 10.1016/B978-0-408-70326-0.50004-1.

[9] A. Muharsyah, S. R. Hayati, M. I. Setiawan, and H. Nurdiyanto, "Sistem Pendukung Keputusan Penerimaan Jurnalis Menerapkan MultiObjective Optimization on The Basis of Ratio Analysis (MOORA)", Jurnal Riset Komputer, vol. 5, no. 1, pp. 19-23, 2018.

[10] S. Anjarwati and M. S. N. Indra, "Sistem Pendukung Keputusan Penerimaan Karyawan Baru Menggunakan Metode Analytical Hierarchy Process Pada PD Tunas Bersama Yamansari Kabupaten Tegal", Jurnal VOI Tasikmalaya, vol. 5, no. 2, pp. 1-10, 2017.

[11] Y. Siagian, "Seleksi Penerimaan Karyawan Baru Menggunakan Metode TOPSIS", Jurnal Mantik Penusa, vol. 2, no. 1, pp. 65-70, 2018.

[12] A. B. Primahudi, F. A. Suciono, and A. A. Widodo, "Sistem Pendukung Keputusan Untuk Pemilihan Karyawan Dengan Metode Simple Additive Weighting Di PT. Herba Penawar Alwahida Indonesia", Jurnal Informatika Merdeka Pasuruan, vol. 2, no. 1, pp. 57-80, 2016.

[13] R. Z. Hasibuan, A. Prahutama, and D. Ispriyanti, "Perbandingan Metode MOORA dan TOPSIS dalam Penentuan Penerimaan Siswa Baru dengan Pembobotan ROC Menggunakan GUI Matlab", Jurnal Gaussian, vol. 8, no. 4, 2019, pp. 462-473

[14] Mesran, R. K. Hondro, M. Syahrizal, A. P. U. Siahaan, R. Rahim, and Suginam, "Student Admission Assesment using Multi-Objective Optimization on the Basis of Ratio Analysis (MOORA)", $4^{\text {th }}$ International Seminar: Research for Science, Technology, And Culture, 2017. 